\title{
Evaluation of Nutrition and Physical Activity Knowledge, Attitudes, Self Efficacy and Behaviors in Teachers and Children after Implementation of the "Healthy Active Kids" Online Program in Australian Elementary Schools
}

\author{
Jennifer A. O'Dea \\ Faculty of Education \& Social Work, University of Sydney, Sydney, Australia \\ Email: jennifer.odea@sydney.edu.au
}

Received 1 October 2015; accepted 23 February 2016; published 26 February 2016

Copyright (C) 2016 by author and Scientific Research Publishing Inc.

This work is licensed under the Creative Commons Attribution International License (CC BY). http://creativecommons.org/licenses/by/4.0/

(c) (i) Open Access

\section{Abstract}

The aims were to examine change in nutrition and physical activity knowledge, self efficacy and attitudes in a cohort of 23 teachers and 304 year 5 and 6 children after the "Healthy Active Kids" online program and to assess any behavioral change in children's self reported nutrition and physical activity behaviors and investigate the predictors of nutrition knowledge gain in teachers and children. Results found significant $(p<0.0001)$ increases in teacher and student knowledge of the five food groups; key nutrients provided by each food group, The Australian Guide to Healthy Eating; food labelling laws, identification of common names for fats, sugars and salts on food labels, food proportions on the Healthy Food Plate and the level and percentage of water in the human body and human brain. Teacher attitudes towards the importance of nutrition and diet and self efficacy related to teaching nutrition in class improved $(p<0.01)$. The final regression model for predictors of the dependent variable, knowledge gain in students was $R=0.53$, Adjusted $R$ square $=0.28(\mathrm{~F}=4.76, \mathrm{p}<0.01)$ indicating that $28 \%$ of the variation in knowledge gain was predicted by the negative (low) Time 1 knowledge. Changes to eating habits reported by children were "drinking more water each day" (89.1\%) and "eating foods from the five food groups each day" (76.2\%); "sharing information about food labels with your family" (52.4\%); "reading food labels when you go shopping" (50.0\%); "changing what is on your dinner plate each night" $(44.2 \%)$; "vegetables that you eat now that you didn't eat before" (42.1\%) and "fruits that you eat now" (39\%). Results suggest that the development of basic nutrition knowledge is still very important for both teachers and students, but that other factors such as self efficacy, empowerment and skill development also 
contribute to nutrition behavior change in children.

\title{
Keywords
}

\author{
Nutrition, Diet, Teacher, School, Education, Knowledge, Attitudes, Self Efficacy, Online Learning
}

\section{Introduction}

The benefits of a nutritious diet for children and adolescents have been well documented in the research literature over many decades, yet many children currently living in Westernised countries do not receive an adequate nutrient intake and are particularly deficient in a diet containing adequate fruits, vegetables, milk, dairy foods and iron-containing foods [1] [2].

Research examining child nutrition data from Australia [3], the United Kingdom [4], and the USA [5], for example, illustrates a continuing pattern of long-term inadequacies in the diets of primary school children.

Many factors are responsible for poor diet and low nutrient intakes in schoolchildren in Westernised countries, and these include social, cultural, economic and educational factors [6]-[9] as well as the role of nutrition knowledge during pregnancy [10] and many intergenerational family factors including intrapersonal, interpersonal, and communicative factors [11].

Recent research published by Jones and Zidenberg in the USA (2015) [12] explored the barriers to nutrition education, nutrition education resources used, and the relationship between nutrition knowledge in public school teachers in California.

The study identified two major barriers to teaching nutrition in the classroom, namely, a lack of instructional time and that nutrition was perceived as an unrelated subject. The teachers in this study were also unaware of many nutrition education resources. Nutrition knowledge was not associated with nutrition lessons but it was positively associated with teaching high school and female gender, and negatively associated with identifying as Hispanic or Latino [12].

In another recent study from California, Fridlund Dunton and her colleagues (2014) [13] evaluated the overall public health impact of the "Shaping Up My Choices" programme, a 10-week school-based nutrition education curriculum developed for third-grade students, using the RE-AIM (Reach, Efficacy, Adoption, Implementation, Maintenance) framework. The results provided support for further nutrition education in schools, including improvements in nutrition knowledge, self-efficacy and intakes of vegetables, fruit (girls only), soda, and lownutrient high-energy foods from pre- to post-survey.

In an early study about barriers to healthy eating and physical activity among schoolchildren by O'Dea (2004) [14], the main barriers were identified by children as convenience, taste and social factors and barriers to physical activity included a preference for indoor activities, low energy and motivation levels, time constraints and social factors. Strategies for overcoming barriers as suggested by the students in the study, included suggestions to enlist support from parents and school staff, better planning and time management skills, self-motivation and nutrition education, restructuring the physical environment and greater variety of PE activities in schools.

One essential educational factor which governments, health educators and school education authorities all agree to be an essential component of strategies for the improvement of children's nutritional intake, is the importance of developing and implementing a school-based nutrition education and physical education curriculum [15]-[17].

The delivery of curricula and inclusion of it in broader educational strategies and interventions have been successful in various formats including traditional classroom delivery as well as those that employ a health promotion approach. Drummond [18] states that the aim of school-based health and nutrition promotion is threefold: to educate by providing information on nutritional needs; to empower students by increasing recognition of and ability to choose nutritious foods; and to enhance life skills by teaching simple meal preparation and introducing cooking lessons.

In addition, recent research suggests that school-based health education programs would be most effective and accessible if they employ interactive online and web-based strategies to engage student learning via online and interactive learning methods [19] and social media options [20]. 
The aims of the current study were to 1) Examine the overall change in nutrition and physical activity knowledge, beliefs and attitudes in a cohort of teachers and children after the "Healthy Active Kids” program; 2) Assess any change in children's self reported nutrition and physical activity behaviors after their involvement in the program and 3) Investigate the predictors of nutrition knowledge gain in teachers and children and to examine whether teacher knowledge gain predicts any of the other student variables.

\section{Methods}

\subsection{Participants}

Participants were primary school teachers $(\mathrm{N}=23,61 \%$ female) and children $(\mathrm{n}=301,56 \%$ female) in school Years 5 and 6 from 12 schools in the Canberra School Region of the Australian Capital Territory of Australia. Teachers volunteered to enrol in a Healthy Active Kids professional development day and their current class of students was also involved in participating in the educational program.

\subsection{Instruments}

Teachers and students completed a pencil and paper self report questionnaire before (Time 1) and after (Time 2) participating in the Healthy Active Kids (HAK) program [21]. The questionnaire measured nutrition knowledge of the 5 food groups (Can you name the 5 Food Groups?); Key nutrients provided by each food group (Can you name 1 key nutrient provided by each Food Group?); The Australian Guide to Healthy Eating (Can you draw the Australian Guide to Healthy Eating in the space below?); Food labelling laws (Name as many items as you can that must be listed by law on a food label or food package in Australia); Identify fats, sugars and salts on food labels (Give 5 common names for types of fat, sugar, salt as found on food labels); Identify the food proportion on the Healthy Food Plate; Identify the level and percentage of water in the human body and human brain (Can you draw the level of the human body and the brain that are made up of water (on the diagrams below)? Do you know the percentage (\%) of each?).

Each nutrition knowledge quiz item was marked by the author and a trained research assistant to achieve a final score. Internal reliability (Cronbach's alpha $\alpha$ ) for the nutrition scores (5 Food groups, Nutrients, Healthy Food Plate, Overall Nutrition Knowledge Score) was moderate in students $(\alpha=0.66)$ and teachers $(\alpha=0.64)$. Internal reliability for the Food Labels scores was moderate $(\alpha=0.56)$ in students and teachers $(\alpha=0.58)$. Internal reliability for the amount of water in the human body and brain was acceptable in students $(\alpha=0.48)$ and teachers $(\alpha=0.44)$.

Attitudes towards diet and nutrition were measured using a 5 point Likert scale as follows_-How do you feel about diet and nutrition? Very important to me; Important to me; Neither important or not important to me; Unimportant to me; Very unimportant to me.

Confidence in teaching about diet and nutrition in the classroom was answered by teachers using a 5 point Likert scale as follows: How confident do you feel about teaching nutrition to your class? Very Confident; A Little Confident; Neutral; Not Confident; Not Confident At All.

Attitudes towards physical activity were assessed using a 5 point Likert scale as follows - How do you feel about sports, exercise and physical activity? Very important to me; Important to me; Neither important or not important to me; Unimportant to me; Very unimportant to me.

Confidence in teaching physical education in class was answered by teachers using a 5 point Likert scale as follows-How confident do you feel about teaching physical education and sports skills to your class? Very Confident; A Little Confident; Neutral; Not Confident; Not Confident At All.

Frequency of physical activity and/or sport on weekdays and weekends were assessed among teachers and students using a 5 point Likert scale as follows-How often do you play sport or do any physical activity on a school day (or weekend day)? Never; Once per month; Every Two weeks; Weekly; 1 - 3 days per week; Every day (Every weekend).

\subsection{Procedure}

The HAK program was approved and accredited by the Teacher Quality Institute of the ACT Government, Department of Education [22]. Teachers completed the Time 1 questionnaire at the beginning of the professional development day. Each questionnaire was assessed by the author and a trained research assistant and mean (SD) 
scores were calculated. Data were entered into an SPSS 22.0 database. Teachers' questionnaire results were given to each participant with appropriate feedback by the author. Teachers were directed to the correct information and general nutrition fact files on the Healthy Active Kids (HAK) website. Student questionnaires were administered to each class of year 5 or year 6 students by their teacher. Results were tabulated by the author and returned to the classroom teacher to discuss with their class.

Health, nutrition and physical activity lessons from the HAK website were implemented by each teacher over a 10 week school period and the questionnaire was completed again at Time 2 by both teachers and students. A summative evaluation questionnaire was also completed by teachers and students to assess their experiences with the HAK program and to obtain feedback. The HAK online program can be accessed in its entirety at www.healthyactivekids.com.au.

\subsection{Statistical Analyses}

Paired t-tests were analysed to determine the means and standard deviations (SD)s for the Time 1 and Time 2 pairs of matched data for students and teachers. Means and SDs was generated from continuous data for nutrition knowledge scores in the categories of five food groups, major nutrients provided by each of the five food groups, the Australian Guide to Healthy Eating, food labelling requirements, names for fats, sugars and salts on food labels, food groups identified on the food plate and hydration of the human body and brain. An overall mean (SD) nutrition knowledge score was also generated. The mean difference in each set of paired scores and P values were then generated from Repeated Measures ANCOVA adjusted for school year in students and years of teaching experience in teachers.

Change in teacher and student attitudes towards nutrition, sports and physical activity and confidence in teaching these topics in the classroom after the Healthy Active Kids teacher training program were analysed using percent change in the 5 point Likert scale using a non-parametric test. The Wilcoxon signed rank test was used in all of these analyses.

Two tailed Pearson Rho correlation coefficients $(\rho)$ were calculated to examine the relationships between knowledge gain and all other variables. Statistically significant correlates were entered stepwise into a linear regression model to determine predictors of knowledge gain. Tests of assumptions found no significant outliers, independence of observations, homoscedasticity and a normal distribution of data, errors and residuals. A p value of $<0.05$ was taken for statistical significance after the adjustment for the Bonferroni correction.

Analysis for any gender differences was performed and as no differences were identified, the male/female data were combined and presented below in results together.

\section{Results}

Questionnaires were completed by 23 teachers $(100 \%$ of teachers who participated in the HAK professional development day) and 301 students at Time 1. Retention at Time 2 was $91.3 \%$ in teachers (one teacher did not teach a class that school term; one teacher went on leave). Retention at Time 2 was $75 \%$ for students (loss of Time 2 data was due to repeated student absences at follow up, changing schools).

Table 1 contains the mean (SD) results for changes in students' nutrition knowledge after participation in the Healthy Active Kids Program. Improvement in nutrition knowledge was statistically significant for all of the variables with the exception of nutrients from the five food groups. The overall nutrition knowledge score almost doubled between Time 1 and Time 2.

Results in Table 2 show the change in teacher's nutrition knowledge after participation in the Healthy Active Kids teacher training program. Each nutrition knowledge variable shows statistically significant improvements between Time 1 and Time $2(\mathrm{p}<0.0001)$.

The change in teacher's attitudes towards nutrition, sports and physical activity and confidence in teaching these topics in the classroom after the Healthy Active Kids teacher training program are shown in Table 3.

Teachers' attitudes towards the importance of health and nutrition and their confidence in teaching about diet and nutrition in the classroom increased significantly $(\mathrm{p}<0.01)$. Attitudes towards physical activity being very important increased from $53.3 \%$ to $73.3 \%$ and confidence in teaching physical education increased from very confident $66.7 \%$ to $80.0 \%$ in teachers, but these improvements did not reach statistical significance on the analyses performed. 
Table 1. Change in student's nutrition knowledge after participation in the Healthy Active Kids program.

\begin{tabular}{ccccc}
\hline & $\begin{array}{c}\text { Time } 1 \\
\text { Mean (SD) }\end{array}$ & $\begin{array}{c}\text { Time } 2 \\
\text { Mean (SD) }\end{array}$ & $\begin{array}{c}\text { Mean difference } \\
(95 \% \text { CI })^{*}\end{array}$ & p value $^{*}$ \\
\hline Five food groups & $3.67(1.09)$ & $4.23(1.07)$ & $0.55(0.29,0.82)$ & $<0.0001$ \\
Major nutrients provided each food group & $2.46(1.90)$ & $2.66(2.04)$ & $0.20(-0.41,0.80)$ & 0.51 \\
Guide to Healthy Eating & $3.70(2.48)$ & $7.06(2.19)$ & $3.36(2.18,4.55)$ & $<0.0001$ \\
Food labelling requirements & $3.15(1.66)$ & $6.00(3.48)$ & $2.79(1.84,3.75)$ & $<0.0001$ \\
Fats on food labels & $0.97(0.84)$ & $2.85(1.69)$ & $1.51(1.08,1.94)$ & $<0.0001$ \\
Sugars on food labels & $1.46(1.10)$ & $3.59(1.44)$ & $1.94(1.55,2.32)$ & $<0.0001$ \\
Salt on food labels & $1.01(0.71)$ & $2.87(1.39)$ & $1.62(1.22,2.02)$ & $<0.0001$ \\
Foods identified on food plate & $2.19(0.68)$ & $2.57(0.56)$ & $0.30(0.09,0.49)$ & $<0.005$ \\
Hydration of human body & $3.04(1.16)$ & $4.04(1.02)$ & $0.82(0.50,1.13)$ & $<0.0001$ \\
Hydration of human brain & $2.17(1.82)$ & $3.72(1.57)$ & $1.49(1.00,2.00)$ & $<0.0001$ \\
Overall nutrition Knowledge score & $16.59(9.53)$ & $32.45(14.47)$ & $14.69(11.92,17.46)$ & $<0.0001$ \\
\hline
\end{tabular}

*Least significant difference (LSD) post-hoc test from repeated measures ANCOVA adjusted for school year.

Table 2. Change in teacher's nutrition knowledge after participation in the Healthy Active Kids teacher training program.

\begin{tabular}{|c|c|c|c|c|}
\hline & $\begin{array}{c}\text { Time } 1 \\
\text { Mean (SD) }\end{array}$ & $\begin{array}{c}\text { Time } 2 \\
\text { Mean (SD) }\end{array}$ & $\begin{array}{l}\text { Mean difference } \\
\quad(95 \% \mathrm{CI})\end{array}$ & $\mathrm{p}$ value \\
\hline Five food groups & $3.86(0.86)$ & $4.86(0.54)$ & $1.00(0.38,1.62)$ & 0.004 \\
\hline Nutrients from each food group & $2.38(1.76)$ & $4.92(0.28)$ & $2.54(1.36,3.72)$ & 0.001 \\
\hline Guide to healthy eating & $3.00(4.14)$ & $8.46(1.27)$ & $5.46(2.84,8.08)$ & 0.001 \\
\hline Food labelling requirements & $5.08(1.32)$ & $8.23(2.35)$ & $3.15(1.66,4.65)$ & 0.001 \\
\hline Fats on food labels & $1.00(0.41)$ & $4.54(0.97)$ & $3.54(2.90,4.18)$ & $<0.0001$ \\
\hline Sugars on food labels & $1.38(0.77)$ & $4.46(0.66)$ & $3.08(2.49,3.66)$ & $<0.0001$ \\
\hline Salt on food labels & $0.70(0.63)$ & $3.62(1.50)$ & $2.92(1.97,3.88)$ & $<0.0001$ \\
\hline Food groups identified on food plate & $2.07(0.73)$ & $2.93(0.26)$ & $0.87(0.51,1.23)$ & $<0.0001$ \\
\hline Hydration of human body & $2.40(0.99)$ & $4.40(0.74)$ & $2.00(1.33,2.67)$ & $<0.0001$ \\
\hline Hydration of human brain & $2.67(2.06)$ & $4.47(1.06)$ & $1.80(0.45,3.15)$ & 0.013 \\
\hline Overall nutrition Knowledge score & $24.27(4.89)$ & $51.0(5.61)$ & $26.73(22.88,30.58)$ & $<0.0001$ \\
\hline
\end{tabular}

Least significant difference (LSD) post-hoc test from repeated measures ANCOVA adjusted for years of teaching. 
Table 3. Change in teacher's attitudes towards nutrition, sports and physical activity and confidence in teaching these topics in the classroom after the Healthy Active Kids teacher training program.

\begin{tabular}{|c|c|c|c|c|}
\hline & & Time $1 \%$ & Time $2 \%$ & p value* \\
\hline \multirow{3}{*}{$\begin{array}{l}\text { Attitude towards health } \\
\text { and nutrition }\end{array}$} & Neutral & 6.7 & - & $0.014^{*}$ \\
\hline & Important & 66.7 & 40.0 & \\
\hline & Very important & 26.7 & 60.0 & \\
\hline \multirow{4}{*}{$\begin{array}{l}\text { Confidence teaching } \\
\text { nutrition in classroom }\end{array}$} & Not confident & 6.7 & - & $0.005^{* *}$ \\
\hline & Neutral & 13.3 & 6.7 & \\
\hline & Little confident & 66.7 & 20.0 & \\
\hline & Very confident & 13.3 & 73.3 & \\
\hline \multirow{3}{*}{$\begin{array}{l}\text { Attitude towards sports and } \\
\text { physical activity }\end{array}$} & Neutral & 6.7 & - & 0.21 \\
\hline & Important & 40.0 & 26.7 & \\
\hline & Very important & 53.3 & 73.3 & \\
\hline \multirow{3}{*}{$\begin{array}{l}\text { Confidence teaching } \\
\text { physical education }\end{array}$} & Neutral & 13.3 & - & 0.16 \\
\hline & Little confident & 20.0 & 20.0 & \\
\hline & Very confident & 66.7 & 80.0 & \\
\hline \multirow{5}{*}{$\begin{array}{l}\text { Frequency of weekday sport } \\
\text { and physical activity }\end{array}$} & Once/month & 9.1 & 6.7 & 0.41 \\
\hline & Every 2 weeks & - & - & \\
\hline & Weekly & 18.2 & 6.7 & \\
\hline & 1 - 3 days/week & 40.9 & 60.0 & \\
\hline & Every day & 31.8 & 26.7 & \\
\hline \multirow{4}{*}{$\begin{array}{l}\text { Frequency of weekend sport } \\
\text { and physical activity }\end{array}$} & Never & 9.5 & - & 0.09 \\
\hline & Once/month & 9.5 & 26.7 & \\
\hline & Every 2 weeks & 4.8 & 20.0 & \\
\hline & Every weekend & 76.2 & 53.3 & \\
\hline
\end{tabular}

$\mathrm{N}=23,{ }^{*}$ Wilcoxon signed rank test, ${ }^{*} \mathrm{p}<0.05,{ }^{* *} \mathrm{p}<0.01$.

Table 4 contains results for the change in students' attitudes towards nutrition and sports and physical activity and their confidence in eating a healthy diet and being physically active after the HAK program. The students' attitudes and confidence increased in a positive direction, but these changes were not statistically significant. Frequency of physical activity was high at both Time 1 and Time 2 in students and there were no observable or statistically significant changes.

Results of correlation (Pearson rho, $\rho$ ) and regression analyses found several variables were negatively correlated with overall knowledge gain from Time 1 to Time 2 in students. These were in order of descending correlation coefficient strength - Time 1 Total Quiz Score $(\rho=-0.79, \mathrm{p}<0.01)$; Time 1 Fats on labels score $(\rho=$ $-0.45, \mathrm{p}<0.01)$; Time 1 water in human body score $(\rho=-0.45, \mathrm{p}<0.01)$; Time 1 knowledge of five food groups score $(\rho=-0.33, \mathrm{p}<0.01)$; Time 1 water in brain score $(\rho=-0.28, \mathrm{p}<0.05)$ and Time 1 confidence in eating a healthy diet score $(\rho=-0.22, \mathrm{p}<0.05)$.

Statistically significant variables were entered into a stepwise linear regression to examine predictors. Time 1 confidence in eating a healthy diet and Time 1 Fats on labels score were not significant and these variables were 
Table 4. Change in students' attitudes towards nutrition and sports and physical activity and their confidence in eating a healthy diet and being physically active.

\begin{tabular}{|c|c|c|c|c|}
\hline & & Time $1 \%$ & Time $2 \%$ & p value* \\
\hline \multirow{4}{*}{$\begin{array}{l}\text { Attitudes towards healthy eating, } \\
\text { diet and nutrition }\end{array}$} & Unimportant & - & 0.8 & 0.08 \\
\hline & Neutral & 12.3 & 17.2 & \\
\hline & Important & 56.6 & 54.9 & \\
\hline & Very important & 31.1 & 27.0 & \\
\hline \multirow{4}{*}{$\begin{array}{l}\text { Confidence in eating a } \\
\text { healthy diet }\end{array}$} & Not confident & 0.8 & 4.1 & 0.17 \\
\hline & Neutral & 16.4 & 11.5 & \\
\hline & Little confident & 50.0 & 39.3 & \\
\hline & Very confident & 32.8 & 45.1 & \\
\hline \multirow{4}{*}{$\begin{array}{l}\text { Attitude towards sports, exercise } \\
\text { and physical activity }\end{array}$} & Unimportant & 2.0 & 1.0 & 0.08 \\
\hline & Neutral & 10.2 & 7.1 & \\
\hline & Important & 22.4 & 22.4 & \\
\hline & Very important & 65.3 & 69.4 & \\
\hline \multirow{4}{*}{$\begin{array}{l}\text { Confidence about being } \\
\text { physically active and fit }\end{array}$} & Not confident & 3.1 & 3.1 & 0.87 \\
\hline & Neutral & 11.2 & 11.2 & \\
\hline & Little confident & 19.4 & 19.4 & \\
\hline & Very confident & 66.3 & 66.3 & \\
\hline \multirow{5}{*}{$\begin{array}{l}\text { Frequency of weekday sport } \\
\text { and physical activity }\end{array}$} & Once/month & 1.0 & 2.0 & 0.41 \\
\hline & Every 2 weeks & 1.0 & 1.0 & \\
\hline & Weekly & 12.2 & 10.2 & \\
\hline & 1 - 3 days/week & 21.4 & 29.6 & \\
\hline & Every day & 64.3 & 57.1 & \\
\hline \multirow{3}{*}{$\begin{array}{l}\text { Frequency of weekend sport } \\
\text { and physical activity }\end{array}$} & Never & 7.1 & 2.0 & 0.09 \\
\hline & Once/month & 1.0 & 7.1 & \\
\hline & Every weekend & 91.8 & 90.8 & \\
\hline
\end{tabular}

*Wilcoxon signed rank test.

removed from the final regression model.

The final regression model for predictors of the dependent variable, knowledge gain in students was $\mathrm{R}=0.53$, Adjusted $\mathrm{R}$ square $=0.28(\mathrm{~F}=4.76, \mathrm{p}<0.01)$ indicating that $28 \%$ of the variation in knowledge gain was predicted by the negative (low) Time 1 knowledge variables included in the model (score of the brain made up of water, score of the human body made up of water, overall score for 5 food groups and total score for items on food labels). Results show that low baseline knowledge predicts knowledge gain in students, but other independent variables such as confidence, gender, school year and teachers’ knowledge do not.

Results of correlation (Pearson rho, $\rho$ ) and regression analyses found none of the independent variables were correlated with overall knowledge gain from Time 1 to Time 2 in teachers. Knowledge gain in teachers did not predict any of the Time 2 independent variables in children. 
Table 5 presents the results from student feedback about the changes to their eating habits and nutrition behaviours after the HAK program. A total of 165 students answered these questions at Time 2. There were no statistically significant gender differences in any responses.

The two major changes to eating habits reported by children were "drinking more water each day" $(89.1 \%)$ and "eating foods from the five food groups each day" (76.2\%).

The next most frequent areas of behaviour change reported were "sharing information about food labels with your family" (52.4\%) and "reading food labels when you go shopping” (50.0\%).

The behavioral changes most frequently listed by children as to "what is on your dinner plate each night" included adding more vegetables/salad (21), eating different foods/more variety (11) and eating healthier food (9).

\section{Discussion}

The first aim of the current study was to examine the overall change in nutrition and physical activity knowledge, beliefs and attitudes in a cohort of teachers and children after their participation in the "Healthy Active Kids" program. The findings indicate that the nutrition education program has a huge impact on the nutritional knowledge of both teachers and students under the categories of the 5 food groups, key nutrients provided by each food group, The Australian Guide to Healthy Eating; food labelling laws, identification of common names for fats, sugars and salts on food labels, food proportions on the Healthy Food Plate and the level and percentage of water in the human body and human brain. The knowledge gains in each of these nutrition knowledge categories were enormous, indicating a doubling of the original baseline scores as well as a doubling of the overall knowledge gain.

Interestingly, significant improvement in attitudes towards the importance of nutrition and diet were observed in the teachers, in addition to increases in their confidence in teaching about food and nutrition in the classroom. This are pleasing results, as they illustrate a broad ranging impact of the teacher professional development as well as the effect of utilising the Healthy Active Kids program in the classroom.

These findings are similar to those reported from Californian primary schools by Fridlund Dunton and her colleagues in 2014 [13] who found improvements in students nutrition knowledge, self-efficacy and increased

Table 5. Student feedback about the changes to their eating habits and nutrition behaviors after participating in the Healthy Active Kids program.

\begin{tabular}{|c|c|c|c|c|c|c|}
\hline & \multicolumn{2}{|c|}{ Male $(n=95)$} & \multicolumn{2}{|c|}{ Female $(n=70)$} & \multicolumn{2}{|c|}{ Total $(n=165)$} \\
\hline & $\begin{array}{l}\text { Yes } \\
\%(n)\end{array}$ & $\begin{array}{l}\text { No } \\
\%(n)\end{array}$ & $\begin{array}{l}\text { Yes } \\
\%(n)\end{array}$ & $\begin{array}{l}\text { No } \\
\%(n)\end{array}$ & $\begin{array}{l}\text { Yes } \\
\%(n)\end{array}$ & $\begin{array}{l}\text { No } \\
\%(n)\end{array}$ \\
\hline $\begin{array}{l}\text { 1) Are there any vegetables that you eat } \\
\text { now that you didn't eat before? } \\
\text { broccoli (10), carrot (9), beans (8) and } \\
\text { capsicum ( } 8 \text { ). }\end{array}$ & $35.1(33)$ & $64.9(61)$ & $51.4(36)$ & $48.6(34)$ & $42.1(69)$ & $57.9(95)$ \\
\hline $\begin{array}{l}\text { 2) Are there any fruits that you eat now } \\
\text { that you didn't eat before? } \\
\text { mangoes (9), oranges ( } 8 \text { ), apples (7), } \\
\text { bananas (5) and blueberries (5). }\end{array}$ & $30.9(29)$ & $69.1(65)$ & $50.0(35)$ & $50.0(35)$ & $39.0(64)$ & $61.0(100)$ \\
\hline $\begin{array}{l}\text { 3) Have you shared the information about } \\
\text { food labels with your family? }\end{array}$ & $53.2(50)$ & $46.8(44)$ & $51.4(36)$ & $48.6(34)$ & $52.4(86)$ & $47.6(78)$ \\
\hline $\begin{array}{l}\text { 4) Have you started reading food labels } \\
\text { when you go shopping? }\end{array}$ & $44.7(42)$ & $55.3(52)$ & $57.1(40)$ & $42.9(30)$ & $50.0(82)$ & $50.0(82)$ \\
\hline $\begin{array}{l}\text { 5) Have you changed what is on your } \\
\text { dinner plate each night? }\end{array}$ & $48.9(46)$ & $51.1(48)$ & $37.7(26)$ & $62.3(43)$ & $44.2(72)$ & $55.8(91)$ \\
\hline 6) Do you drink more water each day? & $86.3(82)$ & $13.7(13)$ & $92.9(65)$ & $7.1(5)$ & 89.1 (147) & $10.9(18)$ \\
\hline $\begin{array}{l}\text { 7) Do you eat foods from the five food } \\
\text { groups each day? }\end{array}$ & $75.8(72)$ & $24.2(23)$ & $76.8(53)$ & $23.2(16)$ & $76.2(125)$ & 23.8 (39) \\
\hline
\end{tabular}


intakes of vegetables and fruit and lower intakes of soda and low-nutrient high-energy foods.

The second aim of our study was to assess any change in children's self reported nutrition and physical activity behaviors after their involvement in the Healthy Active Kids program, which was important for examining the relevance and applicability of our program to the actual health behavior change in students.

Both the male and female students in our cohort reported several important behavior changes including, in descending order, "drinking more water each day" (89.1\%), "eating foods from the five food groups each day" (76.2\%), "sharing information about food labels with your family" (52.4\%) and "reading food labels when you go shopping" (50.0\%).

Importantly, our findings identified no statistically significant gender differences in these healthy behaviour changes, indicating that the Healthy Active Kids program produced positive health behaviours among both boys and girls.

Further to the recommendations from previous research regarding the desired translation of health education programs to positive behaviour changes, the findings of the current study also reflect research directives from governments, school administrators and researchers to design and implement effective school-based nutrition and health education curricula in the classroom and to provide such materials to a broader audience online [15][18].

The findings of the current study suggest that the Healthy Active Kids program was successful in demonstrating improvements in student and teacher nutrition knowledge, attitudes, self efficacy and behaviours because it addressed important curriculum design factors such as educating by providing both information and empowerment to students (and teachers) by increasing nutrition knowledge, self efficacy and cooking skills. These recommendations, which were summarised from the nutrition education research literature by Drummond [18], provided a relevant and solid basis from which to design school-based nutrition education programs such as Healthy Active Kids.

One of the most important units of work in the intervention program was clearly the five lessons about reading food labels and the actual implementation of these newly learned skills by students appears to have resulted in the transfer of learning to behaviour change in students by way of them reading food labels when they go shopping which was reported by more than half of the students.

In addition, previous researchers have suggested that the design of school-based nutrition and health education programs must include parents in order to complement school learning at home [17]-[19] as well as helping to overcome some of the barriers previously reported by children [14]. The reports from more than half of the students in the current study, that they shared the information about food labels with their parents and started reading food labels when they go shopping, suggest that this focus is an important one to include to transfer learning from the classroom to the home and vice versa.

In regard to our final aim, which was to investigate the predictors of nutrition knowledge gain in teachers and children and to examine whether teacher knowledge gain predicts any of the other student variables. Current results suggest that poor baseline knowledge can certainly predict future knowledge gain, but that other factors are also likely to be involved in student learning. Results suggest that the development of nutrition knowledge is still very important for both teachers and students, but that other factors such as self efficacy, empowerment and skill development also contribute to health behavior change in children.

The strengths of the current study include the development of a well-designed and government approved nutrition and physical activity education curriculum (Healthy Active Kids program) as well as having access to teachers for a one-day professional development program and continuing education over the whole school year. Such cooperation and collaboration from school education authorities and teachers assisted in the implementation of this intervention study and also increased the positive outcomes from the current study.

Another strength of the study was the large sample size of teachers and students and the ability to access and follow up the majority of participants.

Despite the strengths, the study has several limitations including the limited geographical catchment in one small territory of Australia, which may not be considered representative of the general Australian population and the lack of a control group. We used statistical procedures such as repeated measures analyses to adjust for these limitations.

The findings of the current study suggest that future research into the efficacy of the Healthy Active Kids program should be undertaken in order to replicate these positive findings among other groups of teachers and different age groups of students in order to establish the efficacy of the curriculum for younger primary school 
children. The development and evaluation of a similar online curriculum for adolescents is also recommended.

\section{Conclusions}

Results suggest that the development of basic nutrition knowledge is still a very important educational issue for both teachers and students, but that other factors such as self efficacy, empowerment and cookery skill development also contribute to nutrition behavior change in children.

The Healthy Active Kids program is currently being delivered as a pilot program to a cohort of trainee teachers in Australian universities to evaluate its usage and to examine the impact of such an education program on the nutrition knowledge, attitudes and behaviors of the undergraduate student teachers and the future impacts on their potential pupils.

\section{Acknowledgements}

The Healthy Active Kids program and professional development were approved by the Teacher Quality Institute of the ACT Department of Education, Professional Learning Provider Approval \#000243 (2014). Signed written consent was obtained from teachers and verbal consent was obtained from parents and students. Healthy Active Kids was developed by Nestlé Australia in partnership with the Australian Institute of Sport (AIS). The full program can be accessed online at www.healthyactivekids.com.au.

The questionnaires can be obtained from the author.

\section{References}

[1] Krebs-Smith, S.M., Guenther, P.M., Subar, A.F., Kirkpatrick, S.I. and Dodd, K.W. (2010) Americans Do Not Meet Federal Dietary Recommendations. Journal of Nutrition, 140, 1832-1838. http://dx.doi.org/10.3945/jn.110.124826

[2] Guenther, P.M., Dodd, K.W., Reedy, J. and Krebs-Smith, S.M. (2006) Most Americans Eat Much Less than Recommended Amounts of Fruits and Vegetables. Journal of the Academy of Nutrition and Dietetics, 106, 1371-1379. http://dx.doi.org/10.1016/j.jada.2006.06.002

[3] National Health and Medical Research Council (2013) Australian Dietary Guidelines. National Health and Medical Research Council, Canberra.

[4] Johnson, L., Mander, A.P., Jones, L.R., Emmett, P.M. and Jebb, S.A. (2008) A Prospective Analysis of Dietary Energy Density at Age 5 and 7 Years and Fatness at 9 Years among UK Children. International Journal of Obesity, 32, 586593. http://dx.doi.org/10.1038/sj.ijo.0803746

[5] Deshmukh-Taskar, P.R., Nicklas, T.A., O'Neil, C.E., Keast, D.R., Radcliffe, J.D. and Cho, S. (2010) The Relationship of Breakfast Skipping and Type of Breakfast Consumption with Nutrient Intake and Weight Status in Children and Adolescents: The National Health and Nutrition Examination Survey 1999-2006. Journal of the Academy of Nutrition and Dietetics, 110, 869-878. http://dx.doi.org/10.1016/j.jada.2010.03.023

[6] Campbell, K.J., Crawford, D.A. and Ball, K. (2006) Family Food Environment and Dietary Behaviors Likely to Promote Fatness in 5-6-Year-Old Children. International Journal of Obesity (London), 30, 1272-1280. http://dx.doi.org/10.1038/sj.ijo.0803266

[7] Booth, S.L., Sallis, J.F., Ritenbaugh, C., Hill, J.O., Birch, L.L., Frank, L.D., Glanz, K., Himmelgreen, D.A., Mudd, M., et al. (2001) Environmental and Societal Factors Affect Food Choice and Physical Activity: Rationale, Influences, and Leverage Points. Nutrition Reviews, 59, S21-S39. http://dx.doi.org/10.1111/j.1753-4887.2001.tb06983.X

[8] Golley, R.K.., Hendrie, G.A., Sarah, A. and McNaughton, S.A. (2011) Scores on the Dietary Guideline Index for Children and Adolescents Are Associated with Nutrient Intake and Socio-Economic Position But Not Adiposity. Journal of Nutrition, 141, 1340-1347. http://dx.doi.org/10.3945/jn.110.136879

[9] Burns, C. (2004) A Review of the Literature Describing the Link between Poverty, Food Insecurity and Obesity with Specific Reference to Australia. Victorian Health Promotion Foundation, Melbourne.

[10] Charlton, K.E., Gemming, L., Yeatman, H. and Ma, G. (2010) Suboptimal Iodine Status of Australian Pregnant Women Reflects Poor Knowledge and Practices Related to Iodine Nutrition. Nutrition, 26, 963-968. http://dx.doi.org/10.1016/j.nut.2009.08.016

[11] Rimal, R.N. (2010) Intergenerational Transmission of Health: The Role of Intrapersonal, Interpersonal, and Communicative Factors. Health Education and Behavior, 30, 10-28. http://dx.doi.org/10.1177/1090198102239256

[12] Jones, A. and Zidenberg, S. (2015) Exploring Nutrition Education Resources, Barriers, and Nutrition Knowledge in California Public School Teachers. Journal of Nutrition Education \& Behavior, 47, 162-169. http://dx.doi.org/10.1016/j.jneb.2014.06.011 
[13] Fridlund Dunton, G., Liao, Y., Grana, R., Lagloire, R., Riggs, N., Chou, C.P. and Robertson, T. (2014) State-Wide Dissemination of a School-Based Nutrition Education Programme: A RE-AIM (Reach, Efficacy, Adoption, Implementation, Maintenance) Analysis. Public Health Nutrition, 17, 422-430. http://dx.doi.org/10.1017/S1368980012005186

[14] O’Dea, J.A. (2004) Why Do Kids Eat Healthy Food? Perceived Benefits of and Barriers to Healthful Eating and Physical Activity among Children and Adolescents. Journal of the American Dietetic Association, 103, 497-501.

[15] UK Department for Education. The National Curriculum for England to Be Taught in All Local Authority-Maintained Schools. http://www.gov.uk/government/collections/national-curriculum

[16] US Government. https://kids.usa.gov/teachers/exercise-fitness-nutrition/index.shtml

[17] Australian Curriculum, Assessment and Reporting Authority (ACARA) (2015) National Health and Physical Education Curriculum. Foundation to Year 10.

[18] Drummond, C.E. (2010) Using Nutrition Education and Cooking Classes in Primary Schools to Encourage Healthy Eating. Journal of Student Wellbeing, 4, 43-54.

[19] Lohse, B. (2013) Facebook Is an Effective Strategy to Recruit Low-income Women to Online Nutrition Education, Journal of Nutrition Education and Behavior, 45, 69-76. http://dx.doi.org/10.1016/j.jneb.2012.06.006

[20] Rosa, K., Hand, R.K., Abram, J.K., Brown, K., Paula, J., Ziegler, P.J., Scott Parrott, J. and Steiber, A.L. (2015) Development and Validation of the Guide for Effective Nutrition Interventions and Education (GENIE): A Tool for Assessing the Quality of Proposed Nutrition Education Programs. Journal of Nutrition Education and Behaviour, 47, 308.e1316.e1. http://dx.doi.org/10.1016/j.jneb.2015.03.003

[21] Healthy Active Kids. www.healthyactivekids.com.au

[22] Teacher Quality Institute (TQI) of the ACT Government Department of Education. http://www.tqi.act.edu.au/ 